\title{
Real Time Sonography as an anatomy teaching aid in undergraduate radiography institutions in Northern Nigeria
}

\author{
Mohammed S Umar ${ }^{1}$, Joseph D Zira², Prince A Ogenyi², Ginikanwa Njokwu², \\ Fati D. Malgwi ${ }^{3}$, Moi A Silas ${ }^{3}$, Shem S Laushongo ${ }^{4}$
}

1. Radiology Department, Aminu Kano Teaching Hospital Kano, Kano State, Nigeria.

2. Radiology Department, Abubakar Tafawa Balewa University Teaching Hospital Bauchi.

3. Department of Medical Radiography, University of Maiduguri, Borno State, Nigeria.

4. Radiology Department, State Specialist Hospital Gombe, Nigeria.

\begin{abstract}
:
Background: Real-time ultrasound scanning is increasing in popularity as a teaching tool for human anatomy because it is non-invasive, offers real-time 3-D anatomy and is cheaper than dissections.

Objectives: To assess real-time ultrasound scanning as a teaching method of human anatomy, and to determine what teaching methods radiography students consider effective for understanding human anatomy.

Materials and methods: One hundred and ten self-administered, structured and pre-tested questionnaires were distributed to Clinical Radiography students (Third, fourth and fifth year)in Northern Nigeria featuring University of Maiduguri and Bayero University Kano. The questionnaire consists of two sections;Demographics and preferred methods of delivery of anatomical information. Participation was voluntary. Comparisons among teaching methods were made using repeated measures ANOVA. Results: A significant difference among the eight delivery methods with 3-D Radiology imaging being as the most preferred method overall (48.17, $\mathrm{p}<0.0001)$ and ultrasound the least $(32.48, \mathrm{p}<0.0001)$. With Duncan's multiple Range test, it is clearly shown that 3-D Radiology imaging differ with mean value(5.2522) followed by Computer programs(5.1292), Anatomic models(4.7593), Laboratory videos(4.5815), textbooks(4.5358), animal dissection(4.2568), lectures(3.2568) and finally ultrasound scan (3.6087), ( $<<0.0001)$.
\end{abstract}

Conclusion: 3-D Radiology imaging is the most preferred method of delivering anatomical information and ultrasound scanning is the least preferred method.

DOI: https://dx.doi.org/10.4314/ahs.v19i2.54

Cite as: Umar MS, Zira JD, Ogenyi PA, Njokwu G, Malgwi FD, Silas MA, Laushongo SS. Real time sonography as an anatomy teaching aid in undergraduate radiography institutions in northern Nigeria. Afri Health Sci.2019;19(2): 2282-2289. https:// dx.doi.org/10.4314/abs.v19i2.54

\section{Introduction}

Anatomy as a basic medical course and being one of the important cornerstones of medicine is essential to radiography students ${ }^{1}$. Traditional way of anatomy teaching using cadavers is universally practiced and has been considered as essential to medical learning ${ }^{2}$. In the conventional setup, anatomy was taught as a pre-clinical component.

\section{Corresponding author: \\ Mohammed S Umar, \\ Radiology Department, \\ Aminu Kano Teaching \\ Hospital Kano, Kano State, Nigeria. \\ Email: umar.sani888@gmail.com}

Despite anatomists' preference for human dissection as a means of teaching anatomy, use of human cadavers is declining. Dissection continues to be a recognized teaching tool, combined with other teaching methods ${ }^{3}$. However, there are two issues. Firstly, technology has advanced so that the use of other methods, such as non-invasive ultrasound scanning, enables a view of human anatomy on a par with dissection. Until now, real-time ultrasound scanning has limited evaluation as a teaching method for anatomy, despite its use in this context in undergraduate radiography education. Secondly, access to human cadavers is expensive and often impractical for universities ${ }^{3-5}$. However, there is an ongoing debate taking place in medical education regarding anatomy teaching methods following the recommendations of the General Medical Council (GMC) that there should be streamlined anato-

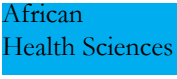

(C) 2019 Umar et al. Licensee African Health Sciences. This is an Open Access article distributed under the terms of the Creative commons Attribution License (https://creativecommons.org/licenses/BY/4.0), which permits unrestricted use, distribution, and reproduction in any medium, provided the original work is properly cited. 
my teaching with integration of clinical sciences ${ }^{6}$. Use of ultrasound as a learning tool may reinforce existing anatomical knowledge and simultaneously allow students to develop skills in interpreting 2D ultrasound images; these skills may be transferable to other imaging modalities which will also be routinely encountered in clinical practice $^{7}$. Currently, ultrasonography as a teaching modality is being explored in anatomy and clinical skills teaching in undergraduate medical education ${ }^{8,9}$. Studying living anatomy using ultrasound adds a dynamic element to the study of anatomy that the cadaver cannot, i.e. visualizing how structures move in a living person during respiration, how blood flows through an organ, observing the depth of structures from the skin surface and appreciating anatomical variation amongst individuals ${ }^{9,10}$. Previous studies have found ultrasound as a helpful educational resource with high student satisfaction for teaching cardiovascular/ renal anatomy and for demonstrating organs, forearm muscles/ vessels ${ }^{11}$. It is reported that using cadavers and imaging together improves the students' ability to identify anatomical structures and provides long term knowledge retention ${ }^{5}$.

Using ultrasound within undergraduate teaching has numerous benefits. Ultrasound enables students to consider the dynamic nature of both anatomy and physiology in real time; students can observe the opening and closing of heart valves, they can appreciate blood flow by observing color Doppler flow, or they can grasp differing tissue densities and the three-dimensional nature of anatomies, something unachievable within a dissecting room or didactic physiology lecture, ${ }^{15}$.

Other methods incorporated for learning anatomy includes 2-D static ultrasound images, anatomical and imaging related textbooks, anatomical models, interactive computer programs demonstrating 3-D anatomy, didactic lectures, 2-D and 3-D post process radiological images, animal organ dissection, construction of 3-D models of anatomy using play dough and videos demonstrating learning activities such as anatomical rhymes, dances and construction of 3-D models 12-15
Given the increased availability and use of portable ultrasound in clinical practice by clinicians, it is anticipated that radiography students will have access to portable ultrasound equipment early in their clinical practice or even during training. There has been considerable research reporting the use of ultrasound imaging among undergraduate healthcare professions in training in medical schools and institutions in the world and there is paucity of literatureon the use of ultrasound as an anatomy teaching aid in undergraduate Radiography institutions in Northern Nigeria.This study will in turn give an insight to radiography institutions, regulatory bodies on the preference use of ultrasound imaging in learning anatomy. Hence the objective of this study is to assess the use of ultrasound scanning as an anatomy teaching aid and to determine the teaching method clinical medical radiography students consider most effective for understanding human anatomy in Northern Nigeria.

\section{Materials and methods}

The study adopted a prospective cross-sectional survey design using a simple random sampling. The study was carried out across a period of six months (December 2016 to June 2017). One hundred and ten self-administered, structured and pre-tested questionnaires were distributed to Clinical Radiography students (Third, fourth and fifth year) of University of Maiduguri (UNIMAID) and Bayero University Kano (BUK) who received anatomy lectures during ultrasound practical demonstrations and during clinical postings were surveyed. However, pre-clinical Radiography students (first and second year) were excluded from the study. The survey instrument was adapted from the Bowman's survey to also include real-time ultrasound scanning as a delivery method ${ }^{2-5}$. The questionnaire consists of two sections; Demographics and preferred methods of delivery of anatomical information. Students were provided an information letter, participation was voluntary and an indication of consent to the study. Students received instruction on how to complete the survey matrix, and the survey was conducted after demonstration class and during clinical postings. All students who completed the survey chose to return it during the next demonstration class and clinical post- 
ings. The survey was set out in a matrix of eight delivery methods (columns) and nine learning aims (rows). The delivery methods were lectures, anatomic models, animal dissection, computer programs, Laboratory videos, 3-D radiology imaging, ultrasound scanning and textbooks. The nine aims were: to impart anatomical information; to provide information for the other science courses; to provide a background for a clinical discipline; to provide an anatomical vocabulary; to provide $3 \mathrm{D}$ appreciation; to encourage learning from experience; to develop team skills; to develop the skill of following complex instructions; and to appreciate anatomical variation. No free text comments were obtained, because the intention was to compare the results with the previous studies where comments were also not collected.

Students placed the numbers one to eight in the matrix for each aim against methods, where the number one indicated there was an excellent match between aim and method and the number eight indicated that the delivery method did not achieve the aim. On a scale of one to eight, one was the "best fit" between delivery method and learning aim, and eight was the "worst fit". The numbers in between indicated a scale, with number becoming a "better fit" as they decreased in value. So the number four was a better fit than five, and so on. Surveys that were incomplete were excluded from the analysis. 92 useable surveys were obtained. The reliability was ensured through a pilot survey conducted amongst clinical radiography students from Bayero University Kano $(n=10)$ who were randomly selected. Moreover, a test-retest method was used. After a 7-days interval, the same clinical radiography students who were selected earlier were asked to answer the same questionnaire. The reliability of the questionnaire is found to be within Crombach's Alpha coefficient of 0.79 (which indicate a good level of consistency and reliability).

Statistical analysis was carried out using Statistical Package for Social Sciences (SPSS) Program (version 20.0 SPSS Inc., Chicago, IL, USA), a p-value of $<0.05$ was considered significant.

\section{Results}

Out of the one hundred and ten administered questionnaires, ninety two were filled appropriately and returned, given a return rate of $83.63 \%$. The analysis was conducted in relation to the specific study objectives: student perceptions of each delivery method, and preferred delivery methods in relation to each of the nine learning aims. First, to compare the overall effectiveness of each of the eight delivery methods we summarized the data as did by bowman's et $\mathrm{al}^{2-5}$ leading to generated reduced matrix of eight columns (the methods) by 92 rows (the students). These are related data because each student gave a score to every delivery method and therefore comparisons among delivery methods should be made with a non-parametric (Friedman) or parametric (repeated measures ANOVA) test. The data are ordinal scale and did not show significant heteroscedasticitywhich was determined using ANOVA Post hoc test, so repeated measures ANOVA were used with students as subjects and the delivery method as the repeated measure as done by Bowman's et $\mathrm{al}^{2-5}$. A priori comparisons (Duncan's multiple Range test, MRT) were used to compare mean satisfaction with ultrasound and the other seven delivery methods. The mean scores possible for each delivery method also ranged from 9.0 (if all students gave a particular method their lowest preference) to 72 (if all students gave a particular method their highest preference) as shown in Table 1.

Table 1: preference by radiography students for eight methods of delivering anatomical information.

\begin{tabular}{|c|c|c|c|c|c|c|c|c|}
\hline & \multirow{2}{*}{\multicolumn{3}{|c|}{ ULTRASOUND }} & \multirow{3}{*}{$\begin{array}{l}\text { ANATOMIC } \\
\text { MODELS }\end{array}$} & \multirow{3}{*}{$\begin{array}{l}\text { COMPUTER } \\
\text { PROGRAMS }\end{array}$} & \multicolumn{3}{|l|}{$3 \mathrm{D}$} \\
\hline & & & & & & RADIOLOGY & & ANIMAL \\
\hline & SCAN & LECTURES & TEXTBOOKS & & & IMAGING & LAB VIDEOS & DISSECTION \\
\hline Mean & 32.48 & 33.67 & 40.82 & 42.83 & 45.39 & 48.17 & 41.23 & 38.31 \\
\hline Ranked & 8 & 7 & 5 & 3 & 2 & 1 & 4 & 6 \\
\hline
\end{tabular}


The ANOVA showed a significant difference among the eight delivery methods with 3D Radiology imaging being the most preferred method overall (48.17, $\mathrm{p}<0.05)$ and ultrasound the least $(32.48, \mathrm{p}<0.05)$. With Duncan's MRT, it is clearly shown that 3D radiology imaging differ with mean value (5.2522) followed by computer programs (5.1292), anatomic models (4.7593), lab videos (4.5815), textbooks (4.5358), animal dissection (4.2568), lectures (3.2568) and finally ultrasound scan (3.6087), $(\mathrm{P}<0.05)$. To specifically examine student perceptions of each delivery method within each of the nine learning aims, the data for each learning aim were also analyzed with repeated measures ANOVA. Here the mean score possible across the 92 students could range from 8.00 (if all students gave a particular method their highest preference) to 1.00 (if all students gave a particular method their lowest preference).

For learning aims one (to impart anatomical information) and two (to provide information for other science courses) there was no significant preference among delivery methods but ultrasound scanning scored lowest in both cases $(\mathrm{P}<0.05)$ as shown in Table 2.

Table 2: preference by radiography students among eight delivery methods in relation to imparting anatomical information and providing information for other science courses

\begin{tabular}{|c|c|c|c|c|c|c|c|c|}
\hline & $\begin{array}{l}\text { ULTRASOUN } \\
\text { DSCAN }\end{array}$ & $\begin{array}{l}\text { LECTURE } \\
S\end{array}$ & TEXTBOOKS & $\begin{array}{l}\text { ANATOMI } \\
\text { C MODELS }\end{array}$ & $\begin{array}{l}\text { COMPUTER } \\
\text { PROGRAM } \\
\text { S }\end{array}$ & $\begin{array}{l}\text { 3D } \\
\text { RADIOLOGY } \\
\text { IMAGING }\end{array}$ & $\begin{array}{l}\text { LAB } \\
\text { VIDEO } \\
S\end{array}$ & ANIMAL DISSECTION \\
\hline $\begin{array}{l}10 \text { Impart anatomical } \\
\text { information }\end{array}$ & 2.18 & 3.12 & 4.27 & 5.07 & 5.71 & 6.40 & 4.76 & 4.78 \\
\hline Ranked & 8 & 7 & 6 & 3 & 2 & 1 & 5 & 4 \\
\hline $\begin{array}{l}\text { To provide information } \\
\text { for other science } \\
\text { course }\end{array}$ & 2.86 & 3.32 & 4.41 & 5.19 & 4.79 & 5.44 & 5.24 & 4.67 \\
\hline Ranked & 8 & 7 & 6 & 3 & 4 & 1 & 2 & 5 \\
\hline
\end{tabular}

From table 3, learning aims three (to encourage learning from experience), four (to develop team skills) ultrasound scan was rated the least (mean score of 2.98 and 3.500, $\mathrm{p}<0.001$ respectively). However, animal dissection and lab. Videos were rated the most preferred delivery method (mean score of 6.03 and 5.78, $<<0.003$ respectively.
For learning objectives fifth and sixth (to follow complex instructions and to appreciate anatomical variation) ultrasound scan was ranked the third and fifth (mean score of 4.86 and $4.29, \mathrm{p}<0.001$ respectively). Lab videos and computer programs were rated the most preferred delivery method (mean score of 5.17 and $5.70, \mathrm{p}<0.001$ respectively). However, lectures and lab videos were rated the least preferred delivery method (mean score of 3.64 and 3.89 respectively) as shown in Table 3 


\begin{tabular}{|c|c|c|c|c|c|c|c|c|}
\hline \multirow{6}{*}{$\begin{array}{l}\text { To encourage } \\
\text { learning from } \\
\text { experience } \\
\text { Ranked }\end{array}$} & \multirow{4}{*}{$\begin{array}{l}\text { ULTRAS } \\
\text { OUND } \\
\text { SCAN }\end{array}$} & \multirow{4}{*}{$\begin{array}{l}\text { LECTU } \\
\text { RES }\end{array}$} & \multirow{4}{*}{$\begin{array}{l}\text { TEXTB } \\
\text { OOKS }\end{array}$} & \multirow{4}{*}{$\begin{array}{l}\text { ANAT } \\
\text { OMIC } \\
\text { MODE } \\
\text { LS }\end{array}$} & \multirow{4}{*}{$\begin{array}{l}\text { COMP } \\
\text { UTER } \\
\text { PROG } \\
\text { RAMS }\end{array}$} & \multirow{4}{*}{$\begin{array}{l}\text { 3D } \\
\text { RADIOL } \\
\text { OGY } \\
\text { IMAGIN } \\
\text { G }\end{array}$} & \multirow{4}{*}{$\begin{array}{l}\text { LAB } \\
\text { VIDE } \\
\text { OS }\end{array}$} & \multirow{4}{*}{$\begin{array}{l}\text { ANIMAL } \\
\text { DISSECTI } \\
\text { ON }\end{array}$} \\
\hline & & & & & & & & \\
\hline & & & & & & & & \\
\hline & & & & & & & & \\
\hline & 2.98 & 3.11 & 3.32 & 4.64 & 5.79 & 5.28 & 4.94 & 6.03 \\
\hline & 8 & 7 & 6 & 5 & 2 & 3 & 4 & 1 \\
\hline $\begin{array}{l}\text { To develop team } \\
\text { skills }\end{array}$ & 3.50 & 4.47 & 3.82 & 3.99 & 4.56 & 5.07 & 5.78 & 5.11 \\
\hline Ranked & 8 & 5 & 7 & 6 & 4 & 3 & 1 & 2 \\
\hline $\begin{array}{l}\text { To follow complex } \\
\text { instructions }\end{array}$ & 4.86 & 3.64 & 4.50 & 4.08 & 4.36 & 5.10 & 5.17 & 4.30 \\
\hline Ranked & 3 & 8 & 4 & 7 & 5 & 2 & 1 & 6 \\
\hline $\begin{array}{l}\text { To appreciate } \\
\text { anatomical variation }\end{array}$ & 4.29 & 3.89 & 4.64 & 4.97 & 5.70 & 5.66 & 3.49 & 3.62 \\
\hline Ranked & 5 & 6 & 4 & 3 & 1 & 2 & 8 & 7 \\
\hline
\end{tabular}

For learning objectives seventh, eighth and ninth (to provide a background for a clinical discipline, to provide an anatomical vocabulary and to provide a $3 \mathrm{D}$ appreciation respectively) ultrasound scanning was ranked sixth, seventh and eighth with mean score of 3.86, 4.20 and 3.77 respectively as shown in Table 4 .

Table 4: preference by radiography students among eight delivery methods in relation to providing a background for a clinical discipline, an anatomical vocabulary and a 3D appreciation of the body.

\begin{tabular}{|c|c|c|c|c|c|c|c|c|}
\hline & $\begin{array}{l}\text { ULTRASOUN } \\
\text { D SCAN }\end{array}$ & $\begin{array}{l}\text { LECTURE } \\
\mathrm{S}\end{array}$ & $\begin{array}{l}\text { TEXTBOOK } \\
\mathrm{S}\end{array}$ & $\begin{array}{l}\text { ANATOMIC } \\
\text { MODELS }\end{array}$ & $\begin{array}{l}\text { COMPUTER } \\
\text { PROGRAMS }\end{array}$ & $\begin{array}{l}\text { 3D } \\
\text { RADIOLOG } \\
\text { Y IMAGING }\end{array}$ & $\begin{array}{c}\text { LAB } \\
\text { VIDEOS }\end{array}$ & $\begin{array}{c}\text { ANIMAL } \\
\text { DISSECTION }\end{array}$ \\
\hline To provide a & & & & & & & & \\
\hline $\begin{array}{l}\text { background for } \\
\text { a clinical } \\
\text { discipline }\end{array}$ & 3.86 & 4.16 & 5.56 & 5.90 & 6.01 & 5.57 & 3.38 & 1.69 \\
\hline Ranked & 6 & 5 & 4 & 2 & 1 & 3 & 7 & 8 \\
\hline $\begin{array}{l}\text { To provide an } \\
\text { anatomical }\end{array}$ & 4.20 & 4.74 & 4.49 & 5.24 & 4.69 & 4.93 & 5.13 & 2.38 \\
\hline vocabulary & & & & & & & & \\
\hline Ranked & 7 & 4 & 6 & 1 & 5 & 3 & 2 & 8 \\
\hline $\begin{array}{l}\text { To provide a } \\
\text { 3D appreciation }\end{array}$ & 3.77 & 4.18 & 5.17 & 3.92 & 4.36 & 5.23 & 4.06 & 5.07 \\
\hline Ranked & 8 & 5 & 2 & 7 & 4 & 1 & 6 & 3 \\
\hline
\end{tabular}


In summary, for five of the nine learning aims ultrasound was rated as the least preferred delivery method (learning aims 1, 2, 3, 4 and 9) and 3D radiology imaging was rated the most preferred delivery method (learning aims 1, 2, and 5) followed by anatomic models and animal dissection (learning aims 3 and 4) and (learning aims 6 and 7) respectively as shown in Table 5 .

Table 5: Summary of delivery methods in relation to learning aims.

\begin{tabular}{|c|c|c|}
\hline \multirow[t]{2}{*}{ Learning aims } & \multicolumn{2}{|c|}{ Preference for delivery methods } \\
\hline & Highest & Lowest \\
\hline 1 To impart anatomical information & 3D Radiology Imaging & Ultrasound Scan \\
\hline 2 To provide information for other science courses & 3D Radiology Imaging & Ultrasound Scan \\
\hline 3 To provide a background for a clinical discipline & Anatomic Models & Animal Dissection \\
\hline 4 To provide an anatomical vocabulary & Anatomic Models & Animal Dissection \\
\hline 5 To provide a $3 \mathrm{D}$ appreciation & 3D Radiology Imaging & Ultrasound Scan \\
\hline 6 To encourage learning from experience & Animal Dissection & Ultrasound Scan \\
\hline 7 To develop team skills & Animal Dissection & Ultrasound Scan \\
\hline 8 To follow complex instructions & Lab. Videos & Lectures \\
\hline 9 To appreciate anatomical variation & Computer Programs & Lab. Videos \\
\hline
\end{tabular}

\section{Discussion}

The use of ultrasound scanning as a teaching tool for anatomy provides an additional level of learning for students. The subject of anatomy teaching within medical curricula is widely debated, with the methods best suited to teaching anatomy a key issue ${ }^{1-4}$. Certainly the concept of using cross-sectional imaging as an adjunct for teaching anatomy is not new. As early as 1985, 68\% of medical schools in the United States were using some form of radiological imaging in undergraduate teaching. Over time the imaging modalities used for teaching has changed with the changing trends of practice of medicine predominantly plain X-rays and fluoroscopy evolving onto cross-sectional imaging such as CT and MRI ${ }^{16}$. Some medical schools have taken this approach to the extreme with completely doing away with cadaveric dissection/prosections from the curricula, exclusively relying on medical imaging, although many would argue against such a radical shift from the established teaching practic$\mathrm{es}^{17}$.
Many studies have been conducted in various parts of the world regarding incorporation of ultrasonography as a teaching method of anatomy in undergraduate medical schools. Kerby et $\mathrm{al}^{4}$ found that dissection was overall most "fit for purpose" in meeting learning outcomes among Nottingham University Students and Imperial College London, but no single teaching modality met all aspects of the curriculum. Bowman et $\mathrm{al}^{2}$ in Australia among students of Central Queensland (CQ) University found ultrasound scan as the most preferred method of delivering anatomical information and dissection was the least favored teaching method, Swarmy and Searle ${ }^{1}$ found that ultrasound scan with cross-sectional images and line diagrams should be used as adjunct to teaching anatomy for medical students in New Zealand, Samarakoon et $\mathrm{al}^{14}$ in Sri Lanka among medical students of University of Colombo also found that cadaveric cross-sectional prosections may help students to understand spatial and radiological anatomy. 
Findings from this study shows that radiography students in Northern Nigeria most preferred 3D radiology imaging as method of delivering anatomical information, but ultrasound scanning being the least preferred method. This is in Contrast with the findings from the study by Bowman's et $\mathrm{al}^{2}$ who stated that real-time ultrasound scanning was the most preferred method of delivery for anatomy classes overall especially compared to computer programs, videos, 3D radiological images and dissection. Specifically, students indicated that ultrasound scanning was the preferred method to encourage learning from experience, to develop team skills, to follow complex instructions and to appreciate anatomical variation. Dissection was the least favored teaching method.Patel and Moxham et al., ${ }^{5}$ who found dissection should be incorporated in an ideal anatomy curriculum with other teaching methods. Their study included a list of six teaching methods but the use of real time ultrasound scanning was not included. Moreover, they surveyed anatomists rather than students, so the student perspective was not considered, nor did they recognize ultrasound scanning as a teaching method for anatomy.Stringer et al, ${ }^{6}$ among medical students in Otago, New Zealand stated that using ultrasound as method of teaching anatomy does not offer hands-on experience; it does provide students with an introduction to the clinical utility of ultrasound and, by focusing on anatomic findings rather than the acquisition of technical imaging skills, reinforces the learning of clinical anatomy.

The disparity from the findings of this study to that of Bowman's et al, ${ }^{2}$ Patel et al, ${ }^{3}$ Kerby et al, ${ }^{4}$ Moxham et $\mathrm{al}^{5}{ }^{5}$, may be because the CQ University student undergoes ultrasound demonstration class more frequently but radiography students in Northern Nigerian Universities were less exposed to ultrasound demonstration class. Another contributing factors may be because: the time taking by instructors in teaching ultrasound scan during demonstration class in Northern Nigerian Universities is too scanty that students don't fully understand the anatomical concept at hand; students were not familiar with the ultrasound machine and appropriate ultrasound setup before the session in order to ensure smooth delivery of the session which is also a key factor; students population which implies appropriate numbers of trained supervisors, and sufficient equipment to teach small groupsis another contributing factor which may be due to the fact that the number of students allocated per ultrasound machine during demonstration session is too much.
One of the implications of this research is that $3 \mathrm{D}$ radiology imaging is a useful tool for teaching anatomy, and ultrasound scan has been rated a poor substitute for the teaching anatomy.

Consequently, since ultrasound scanning has been directly compared to other tools for teaching anatomy, this research provides evidence based to suggest that 3D Radiology imaging might also be useful for teaching anatomy to clinical radiography students. Given the recommendations that some clinical procedures should be conducted under ultrasound guidance, it is inevitable that some students will be unable to achieve competency in performing these clinical skills due to their lack of skills in sonography and consideration must be given to these students.

Given an introductory lecture may help to set the scene, signpost the key points of the anatomy needed and orientate the students to the ultrasound images that will be studied. Moreover, in order to maximize the learning potential of the ultrasound demonstration, the students need to first be primed with the relevant factual information and basic understanding. It is also of paramount importance to use ultrasound machine that has the capability to connect with LCD-projector as it may ease the learning objectives. Therefore, this study recommends designing of optimum learning environment which implies the set up should be small group of people, optimize lighting conditions, more time should be allocated during ultrasound demonstration class and clinical postings, qualify and trained staff should be available to perform the scanseven though effective teaching requires not only a thorough knowledge of the subject matter, but also a high level of interest in teaching and the willingness to devote time and effort to achieve excellence, orientate the students to the relevant anatomy and integrate the session to the wider curriculum and learning outcome, a practical evaluation of the students ability to operate the scanner and correctly interpret scans is the most important measure of achievement with respect to the curriculum. A written examination is also important .

\section{Acknowledgement}

We sincerely acknowledged Victory Sunday Daniel for his support during conceptualization of the manuscript and radiography students from University of Maiduguri, Bayero University Kano for their support during data collection. 


\section{Conclusion}

This study shows that 3D Radiology imaging is the most preferred method of delivering anatomical information and Ultrasound scanning is the least preferred method among clinical radiography students in Northern Nigeria.

\section{Conflict of interest}

Nil.

\section{Contributions of each author}

Study concepts and design- MSU, JDZ, PAO, GN, FDM, ASM, SSL.

Literature research-MSU, JDZ, PAO, GN, FDM, ASM, SSL

Statistical analysis-MSU, JDZ, PAO, GN, FDM, ASM, SSL.

Manuscript preparation- MSU, JDZ, PAO, GN, FDM, ASM, SSL.

Manuscript editing- MSU, JDZ, PAO, GN, FDM, ASM, SSL.

\section{References}

1. Swamy and Searle: Anatomy teaching with portable ultrasound to medical students. BMC Medical Education. 2012 12:99.

2. Bowman A, Lawson C, Mckillup S. The use of real time ultrasound scanning as a teaching method of anatomy in an undergraduate sonography and medical imaging degree in an Australian university. Radiography 2016:22:75-79 3.Patel KM, Moxham BJ. The relationships between learning outcomes and methods of teaching anatomy as perceived by professional anatomists.ClinAnat 2008;21:182189.

4. Kerby J, Shukur ZN, Shalhoub J. The relationships between learning outcomes and methods of teaching anatomy as perceived by medical students. Clin Anat. 2011;24:489-497.

5. Moxham BJ, Moxham SA. The relationship between attitudes, course aims and teaching methods for the teaching of gross anatomy in the medical curriculum. Eur J Anat. 2007;11(Suppl. 1):19-30.
6. Stringer MD, Duncan LJ, Samalia L. Using real-time ultrasound to teach living anatomy: an alternative model for large classes. N. Z Med J 2012;125 (1361):37-45.

7. Brenner E, Maurer H, Moriggi B, Pomaroli A. General educational objectives matched by the educational method of a dissection lab. Anat. 2003; 185:229-230.

8. Hammoudi N, Arangalage D, Boubrit L, et al. Ultrasound-based teaching of cardiac anatomy and physiology to undergraduate medical students. Archives Cardiovasc Dis. 2013; 106:487-491.

9. Ivanusic J, Cowie B, Barrington M. Undergraduate student perceptions of the use of ultrasonography in the study of 'living anatomy'. Anat Sci Educ 2010;3(6):318322.

10. Palma JK. Successful strategies for integrating bedside ultrasound into undergraduate medical education. Mil Med 2015;180.

11. Shapiro RS, Ko PK, Jacobson S. A pilot project to study the use of ultrasonography for teaching physical examination to medical students. Comput Biol Med. 2002; 32:403-409.

12. Miles KA: Diagnostic imaging in undergraduate medical education: an expanding role. Clin Radiol. 2005, 60(7):742-745.

13. Hoppmann R, Michell WE, Carter JB, McMahon C, Lill PH, Brownlee NA,Carnevale KA: Ultrasound in second year pathology medical education. Journal of the South Carolina Academy of Science. 2008, 7(1):11-12.

14. SamarakoonLB,Vithoosan S., Kokulan S., et al. Anatomy of teaching anatomy: Do prosected cross-sections improve students understanding of spatial and radiological anatomy? Anatomy Research International. 2016; 1-4.

15. Griktalis MJ., Scott MP., Finn GM. Twelve tips for teaching with ultrasound in the undergraduate curriculum. Medical Teacher. 2014; 36:19-24.

16. Johnson TH Jr., Medical school radiology teaching and examination methods. Radiology, 1969: 93(2):4 43446.

17. McLachlan JC, New path for teaching anatomy: living anatomy and medical imaging vs. dissection, Anatomical Record-Part B: New Anatomist. 2004: 281 (1):4-5. 